\title{
EDITORIAL
}

\section{Spotlight series on stem cell mobilization: many hands on the ball, but who is the quarterback?}

Leukemia (2010) 24, 1665-1666; doi:10.1038/leu.2010.181

It is well known that hematopoietic stem/progenitor cells (HSPCs) are non-stop travelers throughout the body in both time and space. They circulate in peripheral blood (PB) and lymph during development, moving between major anatomical sites in which hematopoiesis is initiated and/or temporarily active. Starting from blood islands in the yolk sac, HSPCs move through the aortic endothelium, placental vessels and spleen, until they reach the fetal liver in the second trimester of gestation. By the third trimester of gestation they reach their final destination, which is the bone marrow (BM) microenvironment. ${ }^{1}$ The stromal-derived factor- 1 alpha chemokine, which binds to the G-protein coupled, seven-transmembrane-spanning CXCR4 receptors expressed on HSPCs, has been postulated as guiding HSPCs during early development to colonize BM, and later to have a major role in retention of these cells in the BM microenvironment. ${ }^{2,3}$ Later in adult life, a small percentage of HSPCs are continuously released from BM niches into the PB, which may be envisioned as a highway by which HSPCs relocate between distant $\mathrm{BM}$ stem-cell niches to keep the total pool of BM stem cells in balance. It has been demonstrated that under steady-state conditions, circulating HSPCs undergo a circadian rhythm in their circulation in $\mathrm{PB}$, with the peak occurring early in the morning and the nadir at night. ${ }^{4}$ In mice, the basal number of HSPCs circulating in PB is strain dependent.

Thus, it is well demonstrated that, during development and in adult life, HSPCs circulate under steady-state conditions at detectable levels in the PB. The number of circulating HSPCs increases in response to (i) systemic or local inflammation, (ii) strenuous exercise, (iii) stress, (iv) tissue/organ injury and (v) pharmacological agents. ${ }^{5-8}$ The number of HSPCs in PB may increase up to 100-fold after the administration of agents that induce their forced egress into PB, a process known as 'stem-cell mobilization'. The most important mobilizing agents currently employed in the clinic are (i) cytokines (for example, granulocyte colony stimulating factor), (ii) cytostatics (for example, cyclophosphamide), (iii) CXCR4- or very late antigen (VLA)-4-blocking molecules (AMD3100 or BIO4860, respectively) and (iv) certain chemokines (for example, the growth-related oncogene protein- $\beta$ ). ${ }^{9,10}$

Pharmacological mobilization has been exploited in hematological transplantology as a means to obtain HSPCs for hematopoietic reconstitution. HSPCs circulating in PB are currently a preferred source of stem cells for transplantation, because they are easily accessible and - what is important from a clinical point of view - they engraft faster after transplantation than HSPCs harvested from the BM under steady-state conditions. $^{11}$

Several mechanisms have been postulated to orchestrate mobilization, but still more work is needed to better understand this process. In addition to HSPCs, some other rare stem cells (for example, mesenchymal stem cells, endothelial progenitor cells and very small, embryonic-like stem cells) may also appear in the PB during various stress situations. Thus, we can envision stem cells circulating in PB as 'paramedics' involved in immune surveillance (HSPCs) or tissue/organ rejuvenation (mesenchymal stem cells, endothelial progenitor cells and very small, embryonic-like stem cells). For example, during infection circulating colony forming units of granulocytes and macrophages may proliferate in damaged tissues and supply granulocytes, monocytes and dendritic cells to fight the infection. ${ }^{8}$

Evidence is accumulating that mobilization varies with the mechanism that triggers or initiates it: systemic inflammation, tissue/organ injury or pharmacological intervention. Moreover, every mobilizing drug may trigger mobilization by employing overlapping, yet different, mechanisms involving, for example, cytokines, chemokines or small-molecule antagonists of BM-homing receptors.

Overall, the mobilization process has been postulated to be directed by (i) a decrease in The stromal-derived factor-1CXCR4 and VLA-4-VCAM-1 interactions in BM (for example, owing to the release of proteolytic enzymes or after molecular blockage after administration of small molecular antagonists), (ii) release of neurotransmitters from the synapses of the nerves that innervate the BM microenvironement (for example, involving the dopamine and $\beta 2$-adrenergic receptors), (iii) reversal of the trans-endothelial chemotactic gradient between the BM microenvironemnt and plasma, (iv) activation of the coagulation cascade (for example, release of urokinase plasminogen activator receptor (UPAR)) and finally, as recently postulated, (v) activation of the complement cascade. ${ }^{12-16}$ In support of this latter mechanism, it has been observed that mice that do not activate the distal part of the complement cascade display a profound defect in mobilization of HSPCs. ${ }^{16,17}$ Moreover, as reported previously, the complement cascade becomes activated in all mechanisms leading to the mobilization of HSPCs (for example, systemic inflammation, organ injury, as well as administration of all types of mobilizing drugs).

Several types of cells have also been described that are required for mobilization to occur (for example, granulocytes, monomacs and osteoclasts), as well as different basic mechanisms that may affect this process (for example, permeabilization of the BM-blood barrier, release of proteolytic enzymes by myeloid cells in BM (for example, metalloproteinases, elastase and cathepsin-G) and decreased activity of inhibitors of proteolysis (for example, serpins)). At the same time some controversies still exist, for example, about (i) the real involvement of metalloproteinases and other proteolytic enzymes, (ii) the potential participation of osteoclasts and (iii) the molecular nature of major HSPC chemoattractants present in plasma and responsible for egress of HSPCs. ${ }^{18-21}$ For many years it was assumed that the plasma level of The stromal-derived factor-1 was responsible; however, as reported by several investigators, this does not increase significantly during mobilization and thus does not explain the egress of HSPCs. Recent research postulates sphingosine-1 phosphate as a major chemoattractant for HSPCs present in steady-state and mobilized plasma. $8,22,23$ 
However, although we have already gained much information about the mobilization process, there are still several questions to be answered; for example, (i) what are the differences in HSPC mobilization between osteoblastic and endothelial niches, (ii) which factors regulate mobilization of different subsets of HSPCs (for example, short- vs long-term engrafting of stem cells), (iii) how is mobilization regulated for other non-hematopoietic stem-cell types (for example, mesenchymal stem cells, endothelial progenitor cell and very small, embryonic-like stem cells), (iv) are granulocytes always the first cells that egress from the BM and facilitate/precede mobilization of HSPCs, (v) are monocytes that egress from the $\mathrm{BM}$ also involved in permeabilization of the BM-blood barrier (similar to granulocytes), (vi) are HSPCs actively retained in BM by the CXCR-The stromal-derived factor-1, and VLA4-VCAM-1 axes and does this interaction counteract the continuously present chemotactic gradient in plasma and finally (and most important), (vi) what is the molecular basis for the differences between good- and poorly mobilizing patients?

There is no doubt that a proper understanding of the mechanisms of stem-cell mobilization will help to develop more efficient strategies to mobilize these cells for transplantation purposes, which is why Leukemia has decided to publish a new spotlight series of articles devoted to stem-cell mobilization. A hematopoietic stem cell is a cell the fate of which is directly or indirectly affected by several cellular and molecular mechanisms activated during mobilization. This situation resembles an American football game, in which several players touch the ball, but only one of them, the quarterback, calls the play. We invite you to read this spotlight series of papers, written by top experts in the field. The authors, on the basis of their own research, as well as on surveys of the current literature, present their own views on stem-cell mobilization and discuss it from different perspectives. It is hoped that this series of articles will help the reader to make up her/his mind about which mechanism is the real quarterback in the HSPC mobilization game.

\section{Conflict of interest}

The author declares no conflict of interest.

MZ Ratajczak
Stem Cell Biology Program at the James Graham Brown
Cancer Center, Department of Medicine, University of
Louisville, Louisville,
KY, USA
E-mail: mzrata01@louisville.edu

\section{References}

1 Baron MH. Embryonic origins of mammalian hematopoiesis. Exp Hematol 2003; 31: 1160-1169.

2 Ara T, Tokoyoda K, Sugiyama T, Egawa T, Kawabata K, Nagasawa T. Long-term hematopoietic stem cells require stromal cell-derived factor-1 for colonizing bone marrow during ontogeny. Immunity 2003; 19: 257-267.

3 Peled A, Grabovsky V, Habler L, Sandbank J, Arenzana-Seisdedos F, Petit I et al. The chemokine SDF-1 stimulates integrin-mediated arrest of CD34+ cells on vascular endothelium under shear flow. J Clin Invest 1999; 104: 1199-1211.

4 Simón MF, Andrew C, Miriam M, Paul SF. Circadian rhythms influence hematopoietic stem cells. Curr Opin Hematol 2009; 16: 235-242.

5 Luster AD, Alon R, von Andrian UH. Immune cell migration in inflammation: present and future therapeutic targets. Nat Immunol 2005; 6: 1182-1190.
6 Möbius-Winkler S, Hilberg T, Menzel K, Golla E, Burman A, Schuler $G$ et al. Time-dependent mobilization of circulating progenitor cells during strenuous exercise in healthy individuals. J Appl Physiol 2009; 107: 1943-1950.

7 Wojakowski W, Tendera M, Kucia M, Zuba-Surma E, Paczkowska E, Ciosek J et al. Mobilization of bone marrow-derived Oct-4+ SSEA-4+ very small embryonic-like stem cells in patients with acute myocardial infarction. J Am Coll Cardiol 2009; 53: 1-9.

8 Massberg S, Schaerli P, Knezevic-Maramica I, Köllnberger M, Tubo N, Moseman EA et al. Immunosurveillance by hematopoietic progenitor cells trafficking through blood, lymph, and peripheral tissues. Cell 2007; 131: 994-1008.

9 Pelus LM, Fukuda S. Chemokine-mobilized adult stem cells; defining a better hematopoietic graft. Leukemia 2008; 22: 466-473.

10 Papayannopoulou T. Current mechanistic scenarios in hematopoietic stem/progenitor cell mobilization. Blood 2004; 103: 1580-1585.

11 Bonig H, Priestley GV, Oehler V, Papayannopoulou T. Hematopoietic progenitor cells (HPC) from mobilized peripheral blood display enhanced migration and marrow homing compared to steady-state bone marrow HPC. Exp Hematol 2007; 35: 326-334.

12 Levesque JP, Hendy J, Takamatsu Y, Williams B, Winkler IG, Simmons PJ. Mobilization by either cyclophosphamide or granulocyte colony-stimulating factor transforms the bone marrow into a highly proteolytic environment. Exp Hematol 2002; 30: 440-449.

13 Levesque JP, Hendy J, Takamatsu Y, Simmons PJ, Bendall LJ. Disruption of the CXCR4/CXCL12 chemotactic interaction during hematopoietic stem cell mobilization induced by GCSF or cyclophosphamide. J Clin Invest 2003; 111: 187-196.

14 Katayama Y, Battista M, Kao WM, Hidalgo A, Peired AJ, Thomas SA et al. Signals from the sympathetic nervous system regulate hematopoietic stem cell egress from bone marrow. Cell 2006; 124: 407-421.

15 Semerad CL, Christopher MJ, Liu F, Short B, Simmons PJ, Winkler I et al. G-CSF potently inhibits osteoblast activity and CXCL12 mRNA expression in the bone marrow. Blood 2005; 106: 3020-3027.

16 Lee HM, Wysoczynski M, Liu R, Shin DM, Kucia M, Botto M et al. Mobilization studies in complement-deficient mice reveal that optimal AMD3100 mobilization of hematopoietic stem cells depends on complement cascade activation by AMD3100stimulated granulocytes. Leukemia 2010; 24: 573-582.

17 Lee HM, Wu W, Wysoczynski M, Liu R, Zuba-Surma EK, Kucia M et al. Impaired mobilization of hematopoietic stem/progenitor cells in C5-deficient mice supports the pivotal involvement of innate immunity in this process and reveals novel promobilization effects of granulocytes. Leukemia 2009; 23: 2052-2062.

18 Takamatsu Y, Simmons PJ, Moore RJ, Morris HA, To LB, Lévesque JP. Osteoclast-mediated bone resorption is stimulated during shortterm administration of granulocyte colony-stimulating factor but is not responsible for hematopoietic progenitor cell mobilization. Blood 1998; 92: 3465-3473.

19 Kollet O, Dar A, Lapidot T. The multiple roles of osteoclasts in host defense: bone remodeling and hematopoietic stem cell mobilization. Annu Rev Immunol 2007; 25: 51-69.

20 Chang MK, Raggatt LJ, Alexander KA, Kuliwaba JS, Fazzalari NL, Schroder $\mathrm{K}$ et al. Osteal tissue macrophages are intercalated throughout human and mouse bone lining tissues and regulate osteoblast function in vitro and in vivo. J Immunol 2008; 181: 1232-1244.

21 Levesque JP, Liu F, Simmons PJ, Betsuyaku T, Senior RM, Pham C et al. Characterization of hematopoietic progenitor mobilization in protease-deficient mice. Blood 2004; 104: 65-72.

22 Ratajczak MZ, Lee H, Wysoczynski M, Wan W, Marlicz W, Laughlin MJ et al. Novel insight into stem cell mobilization-plasma sphingosine-1-phosphate is a major chemoattractant that directs the egress of hematopoietic stem progenitor cells from the bone marrow and its level in peripheral blood increases during mobilization due to activation of complement cascade/membrane attack complex. Leukemia 2010; 24: 976-985.

23 Ratajczak MZ, Kim CH, Wojakowski W, Janowska-Wieczorek A, Kucia M, Ratajczak J. Innate immunity as orchestrator of stem cell mobilization. Leukemia 2010; 24: 1667-1675. 